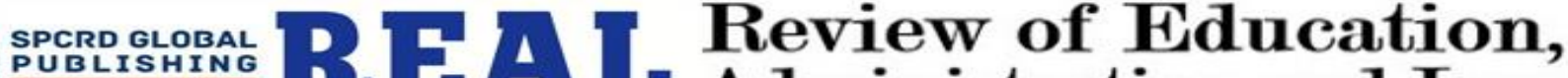 Administration and Law
}

Journal homepage: http://real.spcrd.org ISSN (Print): 2708-1788

\section{The Direct and Indirect Effects of Domestic Violence on the Maternal-Child Relationship \& Intellectual Process of Pre-School Age Children's}

\author{
${ }^{a}$ Hira Ali, ${ }^{\mathrm{b}}$ Hina Ali, ${ }^{\mathrm{c}}$ Maria Shahid, ${ }^{\mathrm{d}}$ Sabira Dilawar \\ ${ }^{a}$ Lecturer, Department of English, University of Sargodha, Pakistan \\ ${ }^{\mathrm{b}}$ Assistant Professor, Department of Economics, The Women University, Multan, Pakistan \\ Email: hinaali@wum.edu.pk \\ ${ }^{\mathrm{c}}$ Lecturer, Department Management Sciences, The Women University, Multan, Pakistan \\ ${ }^{\mathrm{d}}$ Lecturer, Department of Economics, The Women University, Multan, Pakistan
}

ARTICLE DETAILS
History:
Accepted 18 March 2021
Available Online March 2021

\section{Keywords:}

Domestic Violence, Pre-School

Children, Home Environment,

Child Sexual Abuse, Mental

Health, Primary Data, Cognitive

Development

JEL Classification:

I25, $K$ 32, K36, P16

DOI: $10.47067 /$ real.v4i1.126

\begin{abstract}
The study investigated the unswerving besides the incidental effect of domestic violence on a child's Logical Operations. This study took 100 participants also children, whose age is between 3 or 5-year-old in which (44 Boys and 56 Girls) conscripted from the overall society. Domestic violence is used as a dependent variable and negatively related to the home environment and Trauma \& Mental Depression. Children who witness domestic violence have poorer verbal ability whereas controlling the SES and child abuse have significantly affected visual-spatial abilities. The two scores WPPSI- $R$ and PPVT-R score are used for MANCOVA results for primary data for witness and non-witness of domestic violence. In the end, internal vehemence circuitously precious the mutual type of rational skills over the impression on parental downheartedness besides the intellectual superiority of the household atmosphere.
\end{abstract}

(C) 2021 The authors. Published by SPCRD Global Publishing. This is an open access article under the Creative Commons AttributionNonCommercial 4.0

Corresponding author's email address: hinaali@wum.edu.pk

\section{Introduction}

Over 15 years ago, the inquiry on the power of domestic violence on females plus kids consumes thrived. While, the study on preschool-age children is, who witnessing domestic violence are at a risky. For this purpose, most of this article investigation is attentive to child ages mostly 06-12 donkey's years (Levendosky, A., et al. 2002) ${ }^{1}$. Socio-economic status (SES) studies included both preschool children originate that they are large harshly precious than adult children. So that, signifying that early progenies may be the dominantly defenseless effect on local strength.

In Pakistan, numerous studies have instituted that the article on child observers has attentive practically entirely on socio-economic results, although further zones progress like that intellectual functioning has been port uninvestigated. While these studies described that mistreated also deserted 
children, tend to extra uncertain accessory graces as related to other children. Although, this study also a little effort on child-bearing pressure in paternities of autistic families. Subsequently, it is trying to evaluate the scope to which floating a child with autism affects paternities (Cronin and Becher 2015) ${ }^{2}$.

Child sexual abuse (CSA) is precise like a slight practice of sensual satisfaction by alternative once (Dong et al., 2004) ) $^{3}$ Child sexual abuse (CSA) frequently arises in those circumstances somewhere children too bear municipal ferocity, spiritually harsh care supporters (Finkel, Ormrod and Turner 2007) ${ }^{4}$. The result indicates living in that society, they suffer from a warning sign of PTSD. The two types of violence involvements were allied with the trauma symptoms from PTSD.

1. Re-experiencing symptoms; that linked per augmented ferocity as whole natures.

2. Hyperarousal symptoms; that related to using improved fears of vehemence plus exotic ferocity that passed in her/him mommies.

Domestic violence is also a substantial issue whose natural life is exaggerated through these problems. The public, strength, and illegal justice interventions respond to that problem so that an extensive society essentially accepts the expenses. At the same time, as domestic violence is no original miracle, thirty years ago, it has been perceived that growing public awareness also rising radical harmony that approximately wants to be done, even if pardon should be ended is less clear. In a British Crime Survey, in the last year, it was stated that quasi of those who grieved domestic violence were active who matured around 16 years. The study has conducted the result that a high rate of domestic violence exists in different states especially in Pakistan.

Alissa (2001) ${ }^{5}$ demonstrates in the article the unswerving plus unintended possessions of children's logical effects. The study observed the shortest also incidental belongings of local vehemence on preschooler children. The model contained a hundred females besides ages 3-5-year-old children drafted from the overall public. The training further explains that, children around 3.3 million living in the family circle using domestic violence (Carlson 2000). ${ }^{6}$. In pre-school age children, domestic violence had many negative impacts as explained in final research (Graham-Bergmann and Levendosky 2005). ${ }^{7}$

Michael, (2001) ${ }^{8}$ shows in this study assessed domestic violence through a straight and secondary effect in a huge, miscellaneous community. By using the simple self-report, data taken through observational as well as identical assessment apparatuses. Further definitely explained, it was assumed that the quality of the home environment would negatively be related to domestic violence but both, directly and indirectly, related to maternal depression. Also, as it was negative with a home environment that would be predictable to lesser family income above and beyond stumpy intellectual functioning as well as socioeconomic status (SES) of the family. The study indicated the results that children had subordinate verbal abilities than non-witnesses different, which was the observer of domestic violence in the last year, subsequently monitoring the child manipulation plus socioeconomic status(SES).

Alydia (2002) ${ }^{9}$ explains that the study originated that preschool children who live in those families which exhibited large violence with developed approach of communal, interactive, also intellectual difficulties than children in nonaggressive backgrounds. Several studies had demonstrated that shock symptomatology was most important. While scarce revisions designate that superior harshness and occurrence of violence were linked with more serious symptomatology (Kemp 2003). ${ }^{10}$ 
Hutch (2002) ${ }^{11}$ illustrates the violence on suffering indications in an understudied resident. It remained conjectured that perceived domestic violence would have sophisticated post-traumatic stress disorder (PTSD) and performance problematic slashes than children who were alive in folks using domestic violence but had not unswervingly viewed it (Levendosky, and Graham-Bergmann 2000), ${ }^{12}$ The study contributors contained with 100 preschool children with domestic violence that was investigative children's intimate affairs plus communicative operations (Hayat and Zafar 2015). ${ }^{13}$ Besides, pre-school children give the impression to be most defenseless to indications of re-experiencing the suffering besides hyperarousal symptoms.

Deborah and Levendosky (2003) ${ }^{14}$ explicate that the impression of vehemence on affiliation plus effectiveness kids. Even though observing domestic violence as a preschool child was very risky. Most of the investigations had intensive on children eternities 6 to 12 years and participants included 103 children with their mothers. Although, the statistics appropriated the representative which was well organized, but designated that around of the associations were not in the anticipated direction. Domestic violence was negatively related to children's behavior and their mommies in exchanges, nevertheless, it had not encouraged parental description of interactive complications. In conclusion, the child's accessory to the parentages was anticipated to intermediate the possessions of domestic violence on progenies operations.

Levendosky (2002) $)^{15}$ demonstrates, the connection between infant intelligent functioning with domestic violence. Domestic violence harmed more communicative problems as well as negatively expected with human experience that replied a lesser amount of circumstances approximately. Pederson and Moran $^{16}$ observed provision for the spillover proposition, demonstrating that the resentment and struggle in the way of matrimonial affiliation might depressingly inspiration the parent-child relationship. In accumulation, their result was evidenced that respectively of these intermediaries, they might be pretentious by domestic violence, themselves. ${ }^{17}$

Michael and Shapiro $(2004)^{18}$ demonstrate the domestic violence impacts children had succeeded. The overall model constructed on these hypotheses and these were explaining that domestic violence directly distresses parental psychosomatic operational plus circuitously exaggerated nurturing attachment with one another.

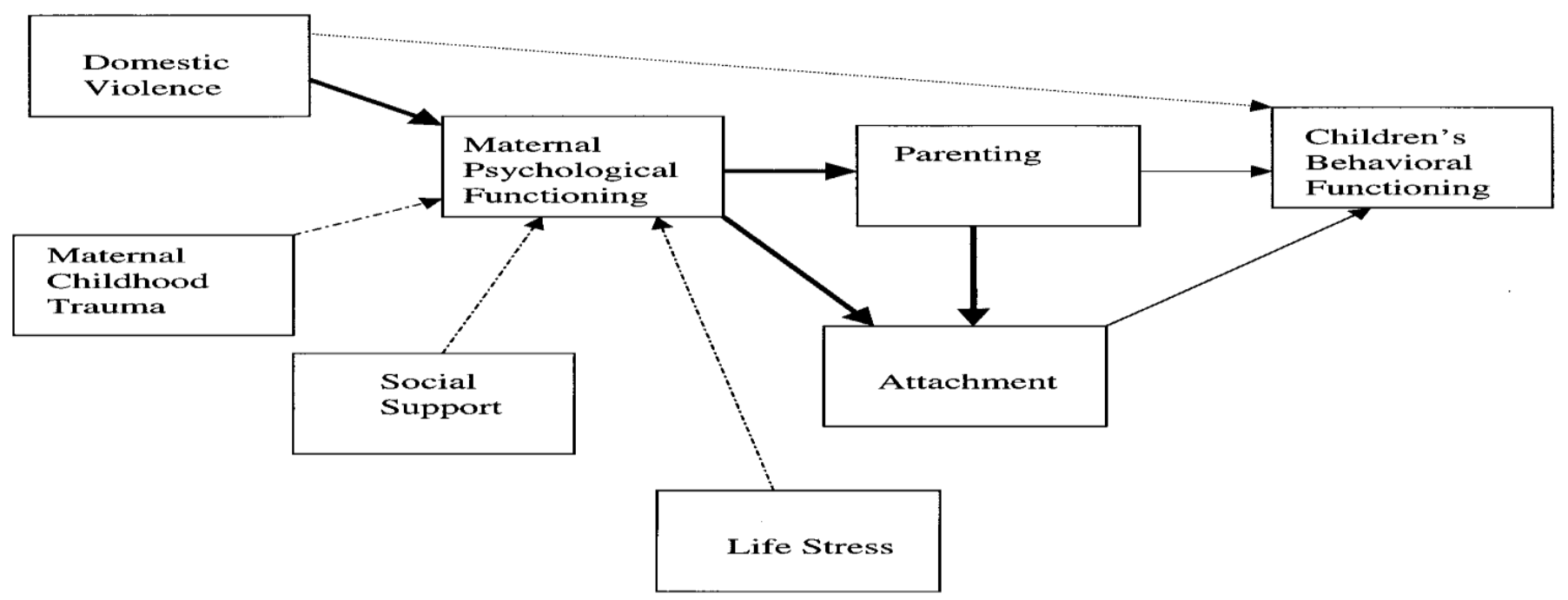

Figure-1: Hypothesized model 
Sabah $(2008)^{19}$ illustrates the momentous anxiety amongst parentages having progenies by Autism. The article evaluated, the side by side parenting stress as well as bracketing factors of trauma among sophisticated children with autism. The study taken included 60 parents that occupied after dissimilar infirmaries also associations. In this study, the female had been represented to be as extra defenseless other than males in the traumatic situation (Gray, 2003). ${ }^{20}$ The final study concluded that it found more pressure in the maternities of kids with autism. The strain was additional in mommies, at what time when children were undeveloped in-phase and especially was further in case of adolescents. So, it was a dire needed to search, in addition to additional explore the problems of developmental disabilities and their mental health concerning parents, which would have experimental benefits for intervention with parentages and relations at hazard among children (Hebdo G, Ameren G, and Wimbley K 2002) ${ }^{21}$. Sajid (2009) ${ }^{22}$ demonstrates the impression of experience to native vehemence on broods and beginning persons. A review of the literature explains that young children had low pressure among their parents. As the children's age increases, the behavioral problem of the disabled child also increases as well as care demanded of that child which was the result of low participation also stumpy to parental welfare. The study investigated the children's problem, whose age was between 4-18 years. The results designated that females passed more stress as compared to males (Mascot, 2002). ${ }^{23}$ These verdicts might have better implications in our philosophy, as parents of their girl-child were additionally apprehensive, as compared to others, about their future.

Olaf son, E (2011) ${ }^{24}$ describes kids' misuse: Influence, also Interferences on children. Child sexual abuse (CSA) was executed by mature plus more developmentally progressive teen-ager and levels of those who identical phase, gamble intimidation was contemporary. The evidence-based intercessions for different varieties of infantile trauma and mal-treatment were primarily recognized by child sexual abuse (CSA) clinicians as well as investigators. Even though well-established treatments for child and mature child sexual abuse (CSA) fatalities happen present, but still evidence-based interventions were required for older teenage CSA victims, exclusively those with consciousness-raising antiquities.

Nadeem (2016) ${ }^{25}$ illustrations the study considers the association amongst emotional security in addition to handling policies with depressed condition children. The study took 120 participants and gender differences were exist here. It was concluded that they were positively correlated with each other. Whereas assembly evaluation among mothers and fathers, the study was instituted that pater conveyed greater that was dynamic circumvention. Devaney $(2015)^{26}$ expressions in the article exploration analysis of local fierceness on toddlers. Now, the study was extensively recognized that children who live in the society of domestic violence were also at the larger menace of suffering abandonment, physical besides sexual abuse. In the end, the study concluded the furthermost vigorous indication of the impression psychosocially, consequences progenies originate beginning investigation of 250 revisions (Buckley 2007). ${ }^{27}$

\section{Theoretical Framework of Parental Stress}

The theory describes that disturbs here mother's trauma, their progenies in addition to their atmosphere (Abettor et al. 2004) ${ }^{28}$. Three domains of parental stress among children have been explaining in this theory.

- The parenting domain is the primary domain. Features associated with anxiety subsequent since the blood relation peculiar involvement are contained within this sphere. These parental issues 
comprise sexual characteristics, intimate top, personality statuses, child growth theories, plus impression approximately nurture a child. Parent's behavior is directly affected by such factors.

- The child domain is the next one that also holds stress associated with the youngster's manner. The traumatic performance of kids is made up of movements such as disobedience, disturbing, inaccuracy, as well as numerous further communication complications of children.

- The Association domain is the third domain. It is a pressure that is connected with maternal besides teen association. According to this theory, the occurrence of tension in somewhat domains can be inspired undesirably with further spheres, although tumbling strain in any domain can have an optimistic effect on the other domains (Deckard, 2004) ${ }^{29}$.

\subsection{Model of Parent-Child Interactive Stress}

The Parenting Stress Index (PSI; 1983, 1995) and the firstborn philosophy which is identified to be parenting stress theory, was industrialized by an investigator. Unfluctuating nevertheless this scheme is the oldest, it still leads to explorations. This theory particularizes intermediaries as well as diplomats linked with the parental strain. It recommends that parental stress is measured by parent physical appearance, child characteristics, also situational features. External life stressors are detected as collective features that can exaggerate parental stress lacking slightly straight significance on parental stress (Abiding, 2005) ${ }^{30}$.

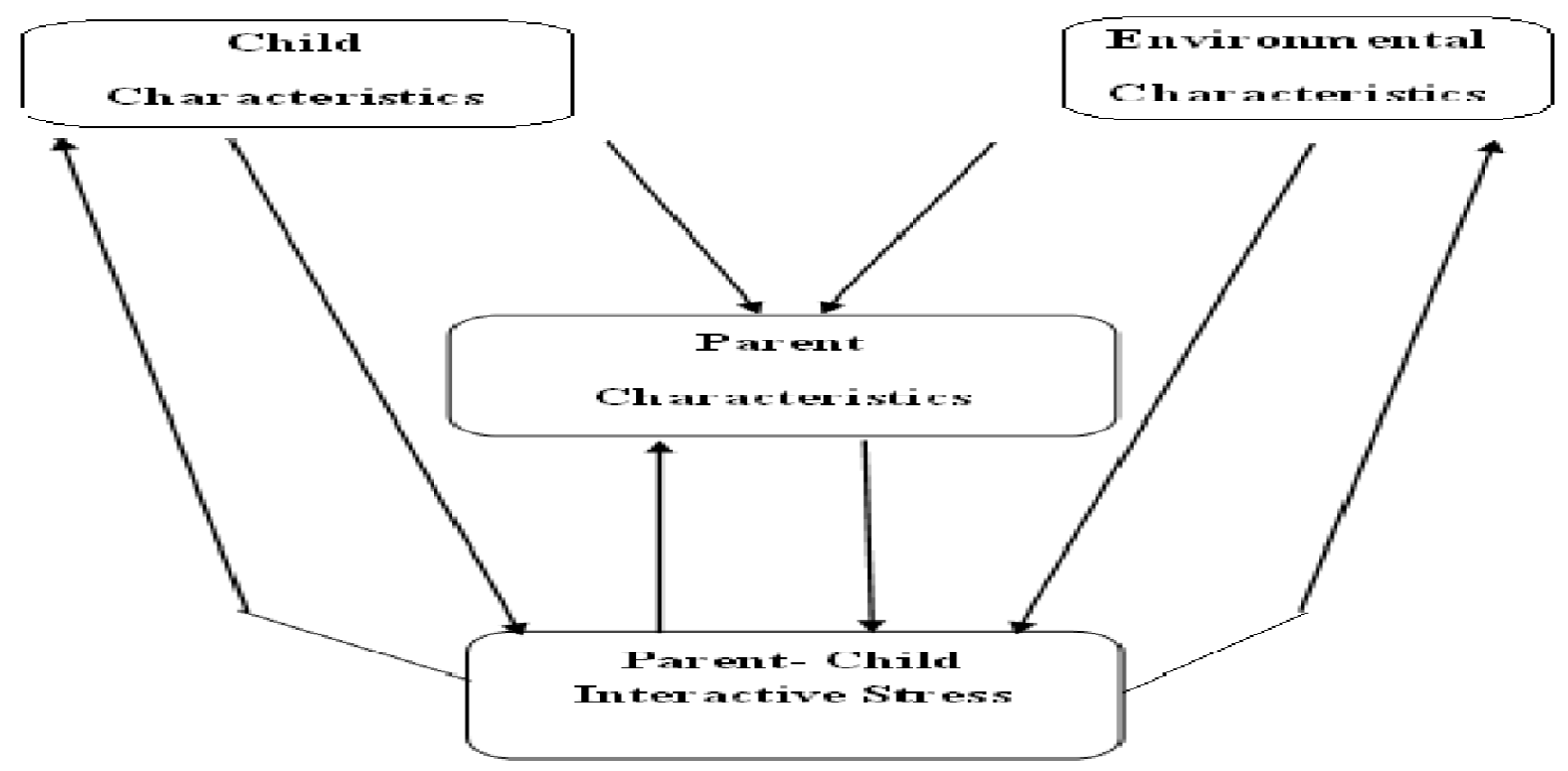

Figure-2: Model of Parent-Child Interactive Stress

Difficulties Faced by Parents of Disabled Children: Gupta (2007) ${ }^{31}$ has designated that this investigation has discovered that parents of progenies with progressive interruptions that specifically associated with child nurture, also involved with greater anxiety (Cranic, Friedrich, and Greenberg, 2000 $)^{32}$. Consequently, the genetic spiritually deactivated around children indicates crucial fluctuations in private circumstances to schedules and generates an unexpected disaster. Because it is disappointing and manufacture approaches that supervision a child with a debility additional characteristic used for the private association. The studies conveyed that children's infection is solitary of the aspects that initiating parental stress. According to Gupta, Mehrotra, \&Mehrotra (2012) $)^{33}$ they originate sophisticated parenting stress amongst parentages of lassies. Furthermore, parents complicated in extra admired professions articulated greater stress as associated with parents affianced in a lesser amount of status professions. Nevertheless, less sustenance is instituted beginning stretched families in 
captivating maintenance of a deactivated child. Parents of children consuming progressive debilities, exclusively in which "Autism Spectrum Disorders (ASDs)", that is defenseless to a greater approach of miseries.

\subsection{The rationale of the Study among Domestic Violence}

Domestic violence has been institute bewildering. While parental stress can be unspecified in standings of disgusting psychosomatic responses, made by parents. Although, it has been familiar as a foremost emotional structure that disturbs a parent's psychological welfare. Consequently, contemporary learning associated the maternal pressure between paternities of pre-school progenies as domestic violence using and without disabilities (Deckard, 2004) ${ }^{34}$. This study also researches domestic violence among pre-school children their intellectual functioning and compared them. Even though preceding revisions have considered this association as relating trauma, domestic violence having in more than a few countries, but no acceptable solution has been found until now in Pakistan.

\section{Research Design}

\subsection{Participants}

The participants consisted of 100 infantile children's in the relatives where internal ferocity occurred. For this article, data taken on individuals' families in which domestic violence currently occurred is studied for this formal research, which is statistically analyzed. The direct relation with domestic violence and indirect relation with the trauma/mental depression and home environment show in this article.

Table 1: Intimate partner violence: A Reality throughout Childhood and Adolescence

\begin{tabular}{|l|l|l|}
\hline Years & Age & Adolescence Violent Death among Children's \\
\hline 2015 & $10-14$ & 3 Times more \\
\hline 2015 & $15-19$ & Particularly weak like 2 or 3 cases \\
\hline 2015 & Below the age of 20 & High like 119,000 \\
\hline
\end{tabular}

UNICEF Report

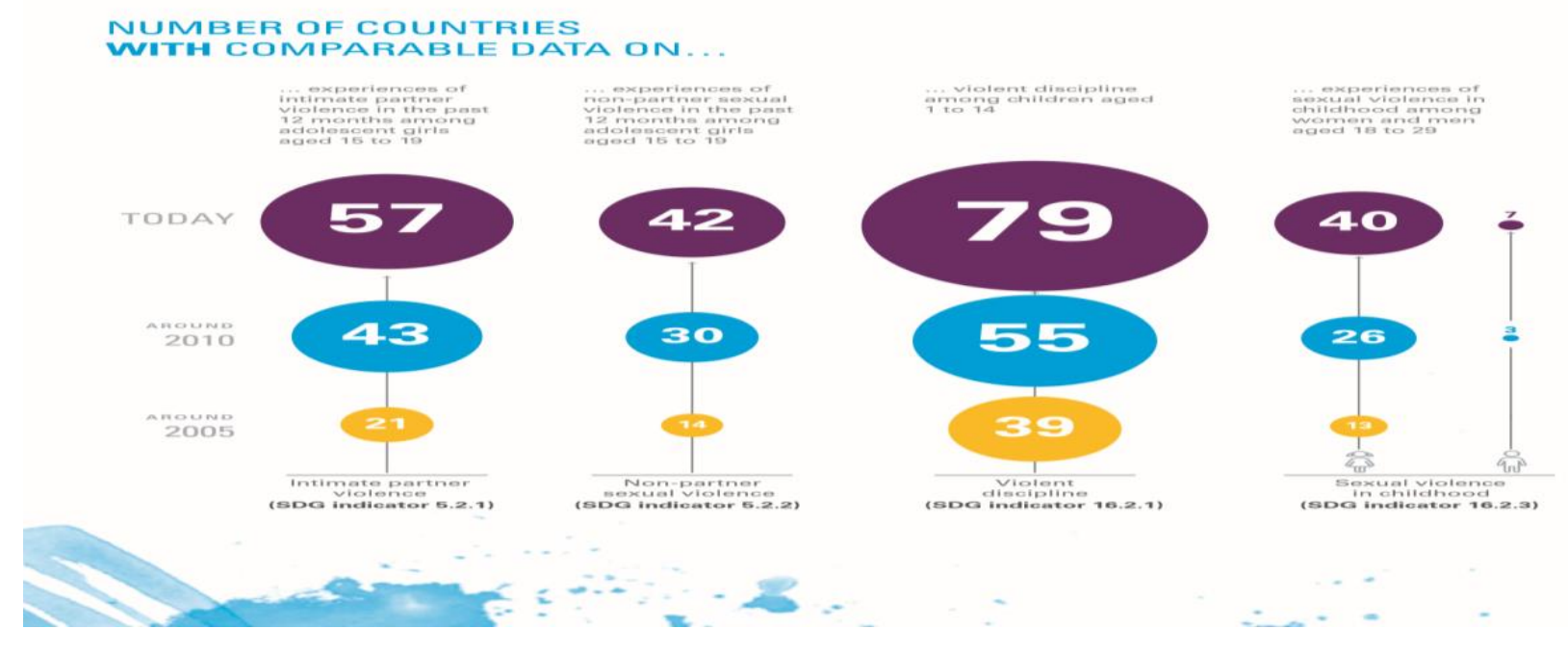

Figure 3: Violence Report during the First years of Childs 


\section{Measures of Article}

\subsection{Domestic Violence}

Domestic violence against a preschool as a maternal-child must be investigated, which includes the different scales of violence like including children's behavioral functioning, maternal depression, and child abuse. For this purpose, taking alpha .80 and .90 are used to assess the children.

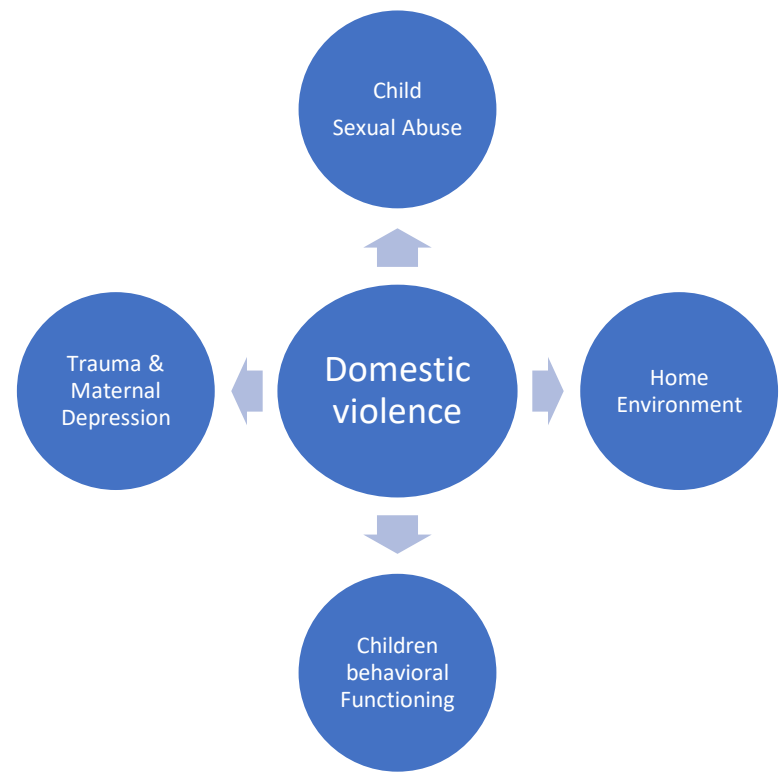

Figure -4: Dependent and Independent Variables

\subsection{Child Sexual Abuse}

The test with alpha .75 was used to measure child abuse and parent-child violence. 19-item research to test the CSA with three ways of dealing which conflict first is reasoning, then verbal aggression and physical aggression, and the child who experienced one or more than one physical abuse is considering to be an "abuse" group. In Pakistan, a total of 3768 cases of CSA were reported in 2015, the number of children abused children to 10 per day which is alarming.

\subsection{Trauma \& Maternal Depression}

Maternal depression with the situation of trauma includes the 4 scales of depression symptoms identically, sleep disturbances, pessimism, changes in appetite as well as depressed mood. The test is identified as self-report, is castoff to evaluate this study of parental depression and coefficient alpha is .87 .

\subsection{Children Behavioral Working}

The test is secondhand to scrutinizing the impact of broods visual and spiritual as well as behavioral abilities which consider the overall ability with the coefficient alpha value is .5 and PPVT-R means is 100 with a standard deviation of $(S D=15)$.

\subsection{Home Environment}

The present homework is afraid of using the household environment of the preschool child of logical working. The scale of the home environment is a rummage-sale, to measure the superiority of home-based situation. On this scale, a higher correlation is between (.30 to .40). Home environmental inventory is collected from home in this study. 


\section{Results}

Data from 100 ( 44 boys and 56 girls) is used for this type of research. The cognitive test is used for testing the violence and nonviolence group with the help of direct on domestic violence and indirect effects on maternal depression and home environment on behavioral or intellectual functioning.

\subsection{MANCOVA Analysis}

MANCOVA test is used for this purpose. MANCOVA compares two or more sets by leveling a factor variable, controlling for a covariate. Here Domestic violence is the only dependent variable, while Child sexual abuse, Home environment, Child behavioral functioning, Trauma, or mental depression are independent variables.

\subsection{Direct Properties of Native Ferocity on Intelligent Working}

The direct effect on internal strength is investigated in this table with the help of the Number of Child (N), Mean (M), Standard derivation (SD) in violence, and nonviolence groups with the help of perceptive assessment scores.

Table-2: Perceptive Assessment points for Vehemence and No-Vehemence Groups

\begin{tabular}{|c|c|c|c|c|c|c|}
\hline \multirow[t]{2}{*}{ Groups } & \multicolumn{3}{|c|}{ Violence Group } & \multicolumn{3}{|c|}{ No-Violence Group } \\
\hline & $\mathbf{N}$ & Mean & SD & $\mathbf{N}$ & Mean & SD \\
\hline Domestic Violence & 31 & 84.84 & 16.69 & 33 & 8.18 & 2.20 \\
\hline Child Sexual Abuse & 10 & 83.80 & 14.60 & 10 & 9.20 & 1.93 \\
\hline Trauma \& Mental Depression & 33 & $93 \cdot 55$ & 18.75 & 36 & 9.08 & 2.93 \\
\hline Children Behavioral Functioning & 21 & 89.8 & 13.56 & 15 & 8.62 & 2.54 \\
\hline Home Environment1 & 5 & 73.02 & 23.06 & 10 & 45.12 & 8.84 \\
\hline Domestic Violence only & & $2.18^{*}$ & & & $16.04^{*}$ & \\
\hline Child Sexual Abuse & & $.23^{*}$ & & & $.02^{*}$ & \\
\hline Trauma \& Mental Depression & & $-.33^{* *}$ & & & $-.31^{* *}$ & \\
\hline Children Behavioral Functioning & & $.12^{* *}$ & & & $.14^{* *}$ & \\
\hline Home Environment1 & & $-.10^{* *}$ & & & $-.15^{* *}$ & \\
\hline
\end{tabular}

\subsection{Cross Effects of Domestic Violence on Intelligent Process}

Net examine the indirect effect of domestic violence on the intellectual process. It is conceptualized that domestic violence is negatively related to home environment and trauma or mental depression with ultimately lowers the contribution of preschool children subsequently regulatory the socioeconomic structure and family income.

Table 3: Domestic Violence and Intellectual Fuctioning

\begin{tabular}{|l|l|l|}
\hline Variables & PPTN-R(n=110) & WPPSI-R(n=104) \\
\hline Adjusted $\mathrm{R}^{2}$ & $.17^{* * *}$ & $.07^{*}$ \\
\hline F Value & $5.58^{* * *}$ & $2.28^{* * *}$ \\
\hline \multicolumn{2}{|l|}{ Result from the series of regression $\mathrm{p}<.05^{*} \cdot \mathrm{p}<.01^{* *} \cdot \mathrm{p}<.0001^{* * *}}$. \\
\hline
\end{tabular}

Relation among domestic violence also progenies rational working in parent a misery besides 
home-grown atmosphere, regression equation is achieved two times; First is PPV-Rration in which (adjusted $\mathrm{R}^{2}=.12, \mathrm{~F}=6.12, \mathrm{P}<.05$ ) and second using the WPPSI- $\mathrm{R}$ score in which (adjusted $\mathrm{R}^{2}=.07, \mathrm{~F}$ $=2.27, \mathrm{p}=.05$ ). In conclusion, domestic vehemence is not straight associated with both the score but indirectly related to each other.

\subsection{Ranking of Violence in Different Fields Concerning Child}

Data collected by UNICEF and the human rights site for every child. Young children who are faced with violence into 3 or 4 ages, they furnished with physical punishment, Psychological aggression, and any violent discipline.

Physical Punishment 63\%

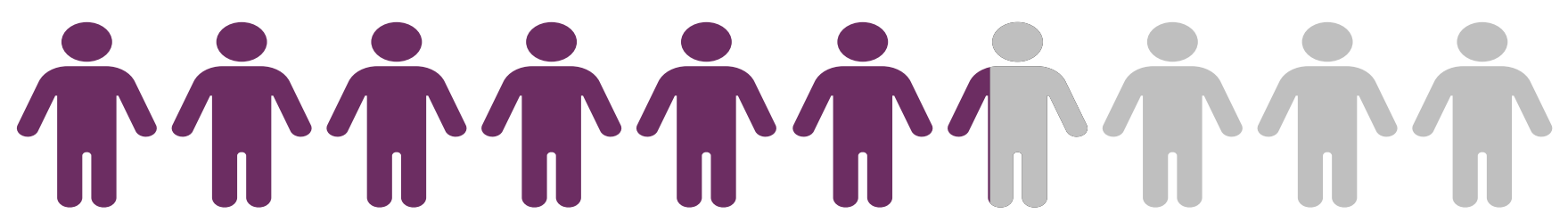

Psychological aggression $67 \%$

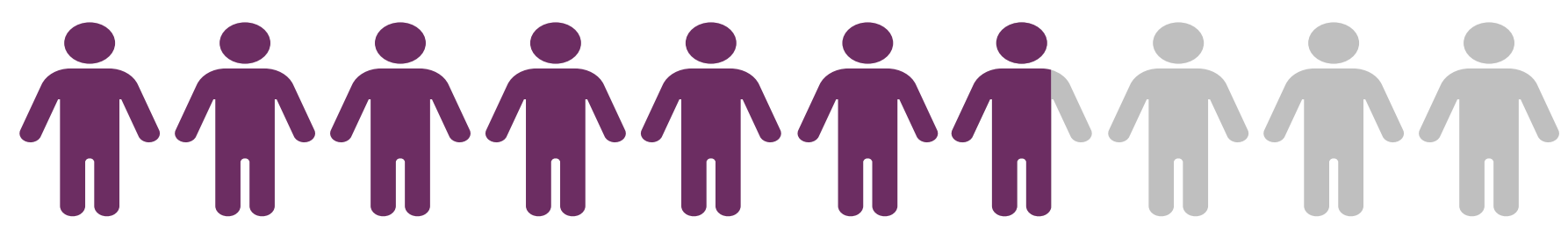

Any violent discipline $75 \%$

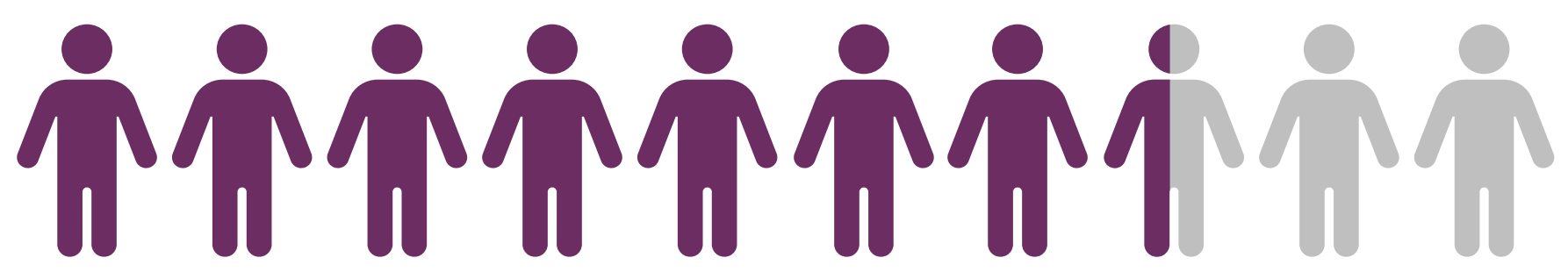

Figure-4: Domestic Violence on age 12 to 23 months Child's

Shouted, or

Screamed
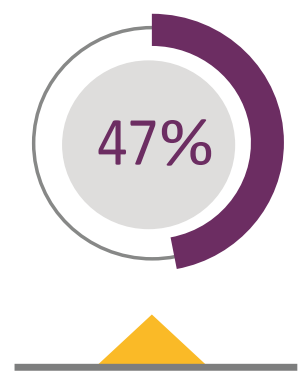

Slapped on the bottom

With bare hand
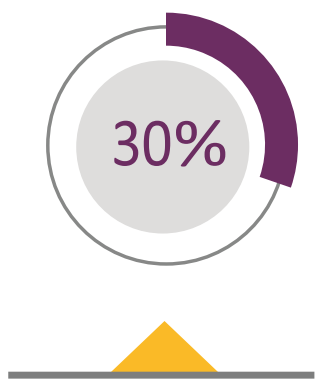

"Dumb/Lazy"

Shouting
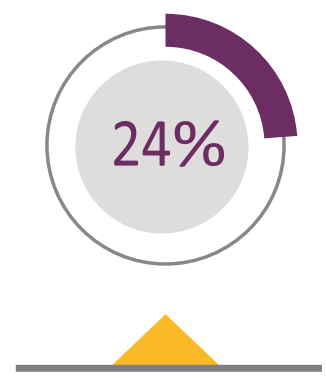

Hit/Slapped on hands, legs

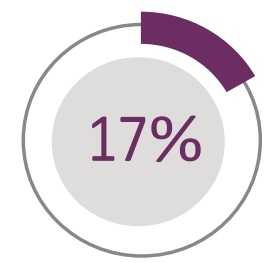




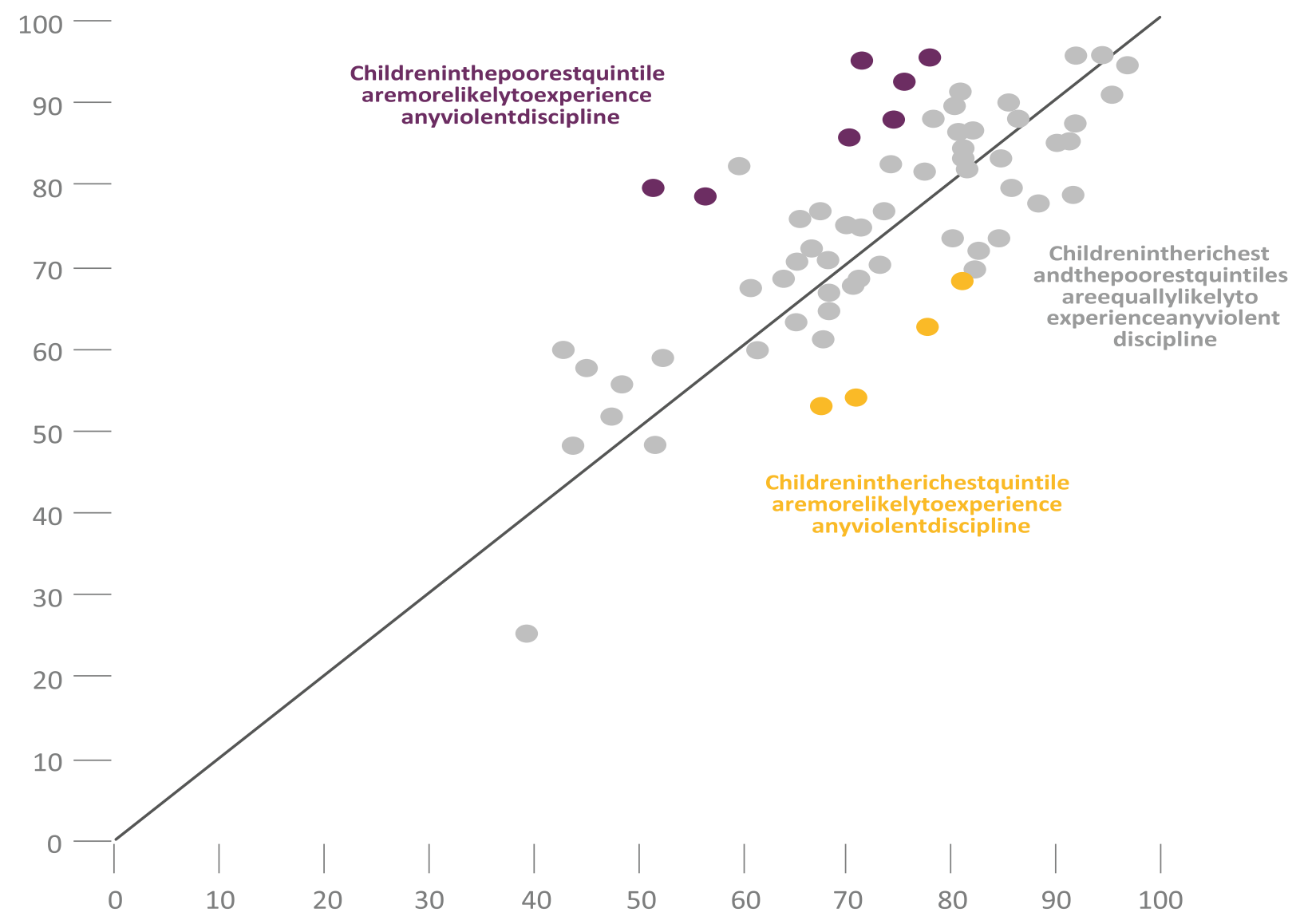

Figure-5: Domestic violence on children whose age 1 to 4 Experienced

\section{Conclusion}

The study researches the domestic violence on preschool child and maternal-child relationship with the help of direct and indirect effects. The study took 100 participants (44 Boys and 56 Girls) for MANCOVA analysis. The study explores that children who have witnessed domestic violence, had expressively subordinate verbal capabilities than on no account, observers subsequently directing for socioeconomic status (SES) also child abuse, but the study is found no transformations in groups on visual-spatial skills.

Child sexual abuse (CSA) frequently arises in those circumstances somewhere children too bear further infantile practices, for instance, child physical abuse; neglect; emotional abuse; as well as the introduction of ingredient abusing plus spiritually harsh attention supporters (GrahamBergmann and Levendosky, 2005) ${ }^{35}$. For the determinations of the current article relied on, data taken only as of those children whose families affected with domestic violence presently taking place were used. The hypothesis of PTSD is used for this article.

Trauma exploration determines to investigate the height of psychosomatic anxiety between these children and underscoring sex modifications in the parental as well as nurturing around the child in their level of anxiety. Age is the most crucial factor in this research. Because they had been well-thought-out in psychological well-being difficulties of parentages. The demography of child sexual abuse (CSA) fluctuates from the further child who mistreatment by masculinity besides community session, that's why the hazardous influences for manifestation and anticipation too 
fluctuated.

In Pakistan, the rate of domestic violence on children is Hight. Because faces poverty due to high population growth, which means that the basic needs of the people are not fulfilled and they never earned much more to the survival of their family. As family size increases, they go to their child to work as child labor as for as domestic violence increases in the recipient countries like Pakistan. The indication of international surveys recommends that about $10 \%$ to $15 \%$ of females that suffering domestic exploitation report it to the law enforcement agency. In literature, the research is dependent on child exploitation, which had exposed adverse properties of misuse on children's logical process.

\section{References:}

Abettor, L. et al. (2004), "Psychological wellbeing and coping in mothers of youths with autism, Down Syndrome, or Fragile X Syndrome', American Journal on Mental Retardation, Vol. 3, pp. 237-254. Abiding, R. R. (2005), “The Parenting Stress Index”, Odessa, FL: Psychological Assessment Resources.

Alissa, C. et. al. (2001), “The direct and direct effects of domestic violence on young children's Intellectual Functioning", Journal of Family Violence, Vol. 16, No. 3, 2001.

Alydia A. et. al. (2002), "Trauma Symptoms in Preschool-Age Children Exposed to Domestic Violence", Journal of Interpersonal Violence, 1 January 2002, pp. 12-45.

Buckley, H., Holt, S., and Whelan, S. (2007), “Listen to Me! Children's Experiences of Domestic Violence”, Journal of Child Abuse Review, Vol. 16, pp. 296-310.

Carlson, B. (2000), “Children's observations of interparental violence”, In Roberts, A. R. (ed.), Battered Women and Their Families, Springer, New York, pp. 147-167.

Cranic, K. A., Friedrich, W. N., and Greenberg, M. T. (2000), "The adaptation of families of mentally retarded children: A model of stress, coping, and family ecology”, American Journal of Mental Deficiency, Vol. 88, pp. 125-38.

Cronin, S., and Becher, E. H., (2015), "What is stress? How do parents experience it? Parents and stress: understanding Experience, Context, and Responses”, University of Minnesota.

Deborah, L. and Levendosky, H. (2003), "The impression of domestic violence on the maternal-child affiliation plus preschool-age children's effectiveness”, Journal of American Psychological Association, May 2003, pp. 893-3200.

Deckard, K. D. (2004), "Parenting stress and child adjustment: Some old hypotheses and new questions", Clinical Psychology: Science and Practice, Vol. 5, pp. 314-332.

Deckard, K. D. (2004), "Parenting stress. New Haven”, Journal of Yale University Press.

Devaney, J. (2015), "Research Review: The Impact of Domestic Violence on Children”, Journal of Irish Probation, Vol. 12, October 2015, pp. 79-94.

Dong, M., et. al. (2004), "The interrelatedness of multiple forms of childhood abuse, neglect, and household dysfunction", Journal of Child Abuse and Neglect, 28, 771-784.

Finkel or, D., Ormrod, R. K., and Turner, H. A. (2007), "Politicization: A neglected component in child victimization", Child Abuse and Neglect, 31(1), 7-26.

Graham-Bergmann, S. A., and Levendosky, A. A. (2005), "Traumatic stress symptoms in children of battered women", Journal of Interpersonal Violence, Vol. 14, pp. 111-128.

Graham-Bergmann, S. A., and Levendosky, A. A. (2005), "Traumatic stress symptoms in children of battered women”, Journal of Interpersonal Violence, Vol. 14, pp. 111-128.

Gray, D. (2003), “Gender and coping: the parents of children with high functioning autism”, Journal of Social Science and Medicine, Vol. 56, pp. 631-642. 
Gupta, V. B. (2007), “Comparison of parenting stress in different developmental disabilities”, Journal of Developmental and Physical Disabilities, Vol. 19 (4), pp. 417-425.

Gupta, V. B., Mehrotra, P., and Mehrotra, N. (2012), "Parental Stress in Raising a Child with Disabilities”, Formerly Asia Pacific Disability Rehabilitation Journal, Vol. 23(2), pp. 41-52

Hastings, R. P. et al., (2005). "Coping strategies in mothers and fathers of preschool and school-age children with autism”, The National Autistic Society, Vol. 9(4), pp. 377-391.

Hayat, I. and Zafar, M. (2015), "Relationship between Psychological Well-Being and Coping Parents with Down syndrome children Strategies among”, International Journal of Humanities and Social Science, Vol. 5, No. 7(1), July 2015.

Hebdo G, Ameren G, and Wimbley K.(2002), "Swedish parents of children with Down's syndrome", Scandinavian Journal of Caring Science, Vol. 16(4), pp. 424-30.

Hutch, C. (2002), "The Impact of Domestic Violence on the Maternal - Child Relationship and PreschoolAgee Children's Functioning", Journal of Family Psychology, 10 October 2003, Vol. 17, No. 3, pp. $275-287$.

Kemp, A., et. al. (2003), "Incidence and correlates of post-traumatic stress disorder in battered women”, Journal of Interpersonal Violence, Vol. 10, pp. 43-55.

Levendosky, A. A., and Graham-Bergmann, S. A. (2000), "Behavioral observations of parenting in battered women”, Journal of Family Psychology, Vol. 14, pp. 80-94.

Levendosky, A. A., et. al. (2002), "Trauma Symptoms in Preschool-age Children exposed to Domestic Violence”, Journal of Interpersonal Violence, Vol. 17, pp. 150-164.

Levendosky, A., et. al. (2002), "Trauma symptoms in preschool-age children exposed to domestic violence", Journal of Interpersonal Violence, 17, 150-164.

Mascot, H. S. (2002), "Exceptional partnerships: Listening to the voices of families", Journal of Preventing school failure, Vol. 46(2), pp. 66-69.

Michael, A. and Shapiro, L. (2004), “The Domestic Violence Impact on Children,”, Journal of family psychology, Vol. 7, pp. 229-245.

Michael, A. et. al. (2001), "The Study assessed the Direct effects of Domestic Violence on Parental Child”, Journal of Family Violence, vol. 10, No. 12, 2001.

Nadeem, M. (2016), "Parental Stress among Parents of Children with and without Disabilities”, Journal of Social Science, Vol. 36, No. 2 (2016), pp. 1281-1289, Pakistan.

Olaf son, E., and Denniston, J. (2011), “Obtaining information from children in the justice system", Juvenile and Family Court Journal, Vol. 59(4), pp. 70-89.

Pederson, D. R., and Moran, G. (2005), "A categorical description of infant-mother relationships in the home and its relation to Q-sort measures of infant-mother interaction”, Journal of Monographs of the Society for Research in Child Development, Vol. 6o(2-3), pp. 111-132.

Sabah, F. (2008), "There is Significant Stress among Parents Having Children with Autism”, 12 Oct 2008.

Sajid, W. (2009), "The impression of exposure to domestic violence on children and young people", Journal of Psychology, Vol. 12, pp. 131-40. 